DOI: https://doi.org/10.47405/mjssh.v5i5.420

\begin{tabular}{|c|c|}
\hline rase & Malaysian Journal of Social Sciences and Humanities (MJSSH) \\
\hline Malaysian Jounal of & Volume 5, Issue 5, May 2020 \\
\hline $\begin{array}{l}\text { (Mumantus } \\
\text { (MSH) }\end{array}$ & e-ISSN : 2504-8562 \\
\hline & $\begin{array}{l}\text { Journal home page: } \\
\text { www.msocialsciences.com }\end{array}$ \\
\hline
\end{tabular}

\title{
Pembelajaran Berasaskan Bahan dalam Mata Pelajaran Sejarah
}

\author{
M. Kaviza ${ }^{1}$ \\ 1Pusat Pengajian Pendidikan dan Bahasa Moden, Universiti Utara Malaysia (UUM) \\ Correspondence: M. Kaviza (kavizakaviza@yahoo.com)
}

\begin{abstract}
Abstrak
Kajian tinjauan ini bertujuan untuk mengenal pasti tahap kesediaan terhadap pembelajaran berasaskan bahan dari aspek pengetahuan, kemahiran dan sikap yang melibatkan seramai 60 orang murid tingkatan empat yang ditentukan berdasarkan teknik persampelan bertujuan merupakan sampel kajian ini. Instrumen kajian ini merupakan soal selidik yang menggunakan skala likert lima mata yang telah disahkan oleh pakar dalam bidang pendidikan sejarah yang berpengalaman dan mempunyai nilai kebolehpercayaan yang baik (0.96). Dapatan kajian ini menunjukkan bahawa tahap kesediaan terhadap pembelajaran berasaskan bahan dari aspek pengetahuan, kemahiran dan sikap berada pada tahap tinggi. Implikasi kajian ini telah mencadangkan kepada pelaksanaan pembelajaran berasaskan bahan dengan berkesan di dalam kelas bagi menyahut cabaran global dalam menggalakkan proses pembelajaran abad ke-21 dalam mata pelajaran sejarah.
\end{abstract}

Kata kunci: pembelajaran berasaskan bahan, kesediaan, mata pelajaran sejarah

\section{Resources-based Learning in History Subject}

\begin{abstract}
This survey study aimed to identify the level of student's readiness towards resources-based learning in terms of knowledge, skills and attitudes which are involving a total of 60 form four students which are selected through purposive sampling technique. The instrument of this study is the five likert scale questionnaires which are verified by the experts and have a good reliability values. The findings of this study indicated that the level of student's readiness towards resources-based learning in terms of knowledge, skills and attitude is high. The implications of this study suggested for implementing resources-based learning successfully in the classroom to respond to global challenges in providing $21^{\text {st }}$ century learning process in history subject.
\end{abstract}

Keywords: resources-based learning, readiness, history subject

\section{Pengenalan}

Perkembangan sistem pendidikan yang menggalakkan penglibatan aktif telah memberikan penekanan terhadap penggunaan bahan sumber pengajaran dan pembelajaran yang lebih dikenali sebagai pembelajaran berasaskan bahan (Doiron \& Davies, 1998; Haycock, 1991; Hill \& Hannafin, 2001; 
Melendres, 2015; Swartz, 2012). Melalui pembelajaran berasaskan bahan, murid-murid dapat menggunakan pelbagai jenis bahan-bahan pembelajaran seperti carta, graf, peta, risalah, laporan lapangan, buku sejarah, risalah, lirik lagu, majalah, jurnal, video, audio, bahan animasi dan grafik dan sebagainya secara aktif dalam meningkatkan kefahaman dan literasi maklumat dan merangsang minat serta mencabar minda intelek dalam klaangan murid walaupun tanpa kehadiran guru di dalam kelas (Kementerian Pendidikan Malaysia [KPM], 2014; Huberman, 2009; Abdul Razaq Ahmad, 2014; Huot, Stroble \& Bazerman, 2004; Mackey, 2002). Adalah diperjelaskan bahawa pembelajaran berasaskan bahan dapat memudahkan pencapaian hasil pembelajaran, membentuk interaksi dua hala antara guru, murid dan bahan pembelajaran, melibatkan aplikasi kemahiran belajar dan menjana pemahaman konsep abstrak (Greenhow, Dexter \& Riedel, 2006; Hannafin dan Hill, 2007; Ryan, Wells, Freeman \& Hallam, 1996; Kong \& So, 2008).

Selain itu, penggunaan bahan-bahan pembelajaran yang bersifat interpretatif dan interaktif dalam proses pengajaran dan pembelajaran dapat mencabar murid untuk berfikir secara kritis dan kreatif serta dapat menjana idea-idea baharu. Hal ini kerana pengupayaan aplikasi pengetahuan, kemahiran dan nilai yang diperolehi daripada proses pembacaan, penganalisisan dan pemahaman dapat membantu muridmurid membuat proses menaakul, membuat refleksi secara berterusan, dapat menyelesaikan masalah yang diutarakan dan membolehkan keputusan yang rasional dilakukan (Neumann, 2015; Gaudelli, 2009; Kelly, 2012; Hendrickson, 2016; Mardina, Umasih \& Winarsih, 2019; KPM, 2014). Tambahan pula, pembelajaran berasaskan bahan yang melibatkan penggunaan bahan-bahan pembelajaran yang bersifat statik mahupun yang bersifat dinamik adalah perlu selari dengan proses penyampaian maklumat dan hasil pembelajaran yang telah dirancangkan (Dodge, 1995; Hill dan Hannafin, 2001). Rentetan daripada pengklasifikasian tersebut, pihak KPM juga telah mengkategorikan bahan sumber pembelajaran dalam proses pengajaran dan pembelajaran kepada dua jenis iaitu bahan sumber berstuktur dan bahan sumber tidak berstruktur. Bahan sumber berstruktur merupakan bahan-bahan pembelajaran yang telah disediakan oleh pihak KPM seperti buku teks, bahan-bahan digital, dan sebagainya, manakala bahan sumber tidak berstruktur pula terdiri daripada bahan-bahan seperti keratan akhbar, jurnal, majalah bahan-bahan dari internat (KPM, 2014).

Sungguhpun begitu, penggunaan bahan pembelajaran dalam mata pelajaran sejarah merupakan suatu yang disarankan dan merupakan suatu pilihan yang tepat selaras dengan matlamat kurikulum sejarah untuk membentuk warganegara Malaysia yang arif dan peka dengan ilmu sejarah. Hal ini kerana displin ilmu sejarah merupakan displin ilmu yang berpaksikan kepada mencari kebenaran tentang masa lalu untuk memupuk nilai keperibadian mulia dan semangat kewarganegaraan serta menjadikan pengajaran yang diperolehi daripada sejarah sebagai iktibar untuk membina kesedaran kebangsaan serta cinta akan negara (Pusat Perkembangan Kurikulum [PPK], 2018). Sehubungan dengan itu, adalah tidak dapat dinafikan bahawa penggunaan bahan-bahan seperti dokumen, peta, majalah, buku sejarah, dokumentari, risalah, poster, catan, artifak, filem sejarah, surat khabar dan sebagainya (Cummings, 2011; Howard, 2012; Godsell, 2019; Barton, 2005; Brown \& Dotson, 2007) merupakan antara bahanbahan pembelajaran yang boleh digunakan dalam mata pelajaran sejarah dalam menggalakkan muridmurid untuk membaca, mentafsir, membanding, menganalisis, menghubung kait dan menginterpretasi, mensintesis maklumat bagi membina pengetahuan baru dan menjana kemahiran berfikir kritis dan kreatif (Cuenca \& Zaker, 2019; Gaffield, 2003; Nokes, 2017; Bickford II \& Bickford, 2015; Wiley \& Voss, 1999; Samuelson \& Wendell, 2016).

Walaubagaimanapun, strategi pembelajaran berasaskan bahan kini semakin mendapat perhatian dalam kalangan para pendidik selaras dengan perkembangan strategi pembelajaran abad ke-21 yang memfokuskan kepada aplikasi pendekatan berpusatkan murid yang semakin meluas dilaksanakan dalam pendidikan sejarah pada peringkat nasional dan global (Halida Yu, A. Abrizah \& Mad Khir Johari Abdullah Sani, 2016; Reisman, 2012; Bickford III, 2010; Nokes, 2014; Reisman \& Fogo, 2016; Dutt-Doner, Cook-Cottone \& Allen, 2007; Hover, Hicks, \& Dack, 2016). Namun, terdapat satu keperluan untuk memastikan sama ada murid-murid telah bersedia untuk menerima idea pelaksanaan strategi pembelajaran berasaskan bahan disebabkan oleh murid-murid adalah berperanan sebagai agen penerima perubahan kepada proses pelaksanaan kurikulum, pedagogi dan pentaksiran pada peringkat sekolah. Hal ini kerana keberkesanan pelaksanaan proses pembelajaran berasaskan bahan dalam mata pelajaran sejarah adalah bergantung kepada kesediaan dan penerimaan murid-murid yang positif 
terhadap kreativiti guru-guru sejarah dalam memilih bahan, menyusun kandungan dan merancang aktiviti pengajaran dan pembelajaran yang dapat meningkatkan penyertaan aktif murid dengan penerapan pengetahuan, kemahiran dan nilai secara berterusan. Maka, terdapat satu kelompongan kepada pengkaji dalam kajian ini untuk meninjau isu sejauh manakah tahap kesediaan murid-murid tingkatan empat yang masih berada dalam proses penyesuaian perubahan dalam pelaksanaan kurikulum baharu iaitu Kurikulum Standard Sekolah Menengah (KSSM) terhadap pembelajaran berasaskan bahan dalam mata pelajaran sejarah.

\section{Objektif Kajian}

Objektif kajian ini ialah untuk mengenal pasti tahap kesediaan terhadap pembelajaran berasaskan bahan dari aspek pengetahuan, kemahiran dan sikap.

\section{Soalan Kajian}

Soalan kajian ini ialah:

1. Apakah tahap kesediaan terhadap pembelajaran berasaskan bahan dari aspek pengetahuan, kemahiran dan sikap?

\section{Metod Kajian}

Kajian berbentuk tinjauan ini melibatkan seramai 60 orang murid Tingkatan Empat sebagai sampel kajian yang dipilih melalui teknik persampelan bertujuan dari sebuah sekolah menengah harian. Soal selidik yang diadaptasi yang telah disahkan kesahan kandungan serta konstruknya oleh dua orang pakar penilai dalam bidang pendidikan sejarah merupakan instrumen kajian ini. Nilai Cronbach Alpha iaitu 0.96 bagi soal selidik telah menunjukkan bahawa instrumen tersebut mempunyai nilai kebolehpercayaan yang baik dan boleh diterima dalam kajian ini (Nunnally, 1978). Data kajian ini dianalisis secara statistik deskriptif melalui perisian IBM SPSS. Interpretasi tahap kesediaan dalam kajian ini ditentukan melalui interpretasi tahap yang diberikan oleh Jamil Ahmad (2002) seperti ditunjukkan pada Jadual 1.

Jadual 1: Interpretasi Min dan Tahap

\begin{tabular}{cc}
\hline Skor Min & Tahap \\
\hline $3.67-5.00$ & Tinggi \\
$2.34-3.66$ & Sederhana \\
$1.00-2.33$ & Rendah \\
\hline Sumber: Adaptasi daripada Jamil Ahmad (2002)
\end{tabular}

\section{Dapatan dan Perbincangan Kajian}

\section{Tahap Kesediaan Terhadap Pembelajaran Berasaskan Bahan}

Berdasarkan Jadual 2, tahap kesediaan terhadap pembelajaran berasaskan bahan $(M=4.09, S D=0.60)$ berada pada tahap tinggi. Justeru, dapat dirumuskan bahawa tahap kesediaan terhadap pembelajaran berasaskan bahan dalam kalangan murid berada pada tahap tinggi dalam kajian ini. Dapatan kajian ini yang menunjukkan tahap kesediaan murid terhadap pembelajaran berasaskan bahan dalam mata pelajaran sejarah yang berada pada tahap tinggi adalah konsisten dengan dapatan kajian Nasyimah Ismail dan Zamri Mahamod (2016) yang telah melaporkan bahawa tahap kesediaan murid sekolah menengah terhadap kemahiran berfikir aras tinggi dalam mata pelajaran bahasa melayu adalah tinggi 
dan kajian Tuan Rahayu Tuan Lasan, Mohd Adari Che Noh dan Mohd Isa Hamzah (2017) yang melaporkan bahawa tahap kesediaan murid tingkatan empat terhadap kemahiran berfikir aras tinggi dalam mata pelajaran Tasawur Islam adalah tinggi serta kajian Tajularipin Sulaiman dan Mohd Majid Konting (2014) yang membuktikan bahawa tahap kesediaan murid tahun satu terhadap pengajaran kemahiran proses sains dalam bahasa inggeris adalah tinggi iaitu 67.20 peratus bagi kemahiran komunikasi, 90.30 peratus bagi kemahiran pengelasan, 58.60 peratus bagi kemahiran pemerhatian dan 60.50 peratus bagi kemahiran meramal yang menyokong dapatan kajian ini secara tidak langsung. Walaubagaimanapun, dapatan kajian ini didapati bertentangan dengan kajian Sri Wahyuni Marimum dan Anuar Ahmad (2019) yang melaporkan tahap kesediaan murid melayu yang mempelajari mata pelajaran sejarah di sekolah aliran cina (SRJKC) dengan menggunakan bahasa mandarin adalah sederhana dan kajian Noraini Bidin dan Zamri Mahamod (2016) secara mixed method yang melibatkan 10 orang murid telah melaporkan bahawa murid-murid yang mempelajari bahasa melayu mempunyai tahap kesediaan yang sederhana terhadap pelaksanaan pentaksiran berasaskan sekolah.

Jadual 2: Kesediaan Terhadap Pembelajaran Berasaskan Bahan

\begin{tabular}{lllcc}
\hline Konstruk & $\boldsymbol{N}$ & $\begin{array}{c}\text { Min } \\
(\boldsymbol{M})\end{array}$ & $\begin{array}{c}\text { Sisihan Piawai } \\
(\boldsymbol{S D})\end{array}$ & Tahap \\
\hline Kesediaan & 60 & 4.09 & 0.60 & Tinggi \\
\hline
\end{tabular}

\section{Tahap Kesediaan Terhadap Pembelajaran Berasaskan Bahan dari Aspek Pengetahuan}

Berdasarkan Jadual 3, tahap kesediaan terhadap pembelajaran berasaskan bahan dari aspek pengetahuan $(M=4.10, S D=0.66)$ berada pada tahap tinggi. Justeru, dapat dirumuskan bahawa tahap kesediaan terhadap pembelajaran berasaskan bahan dari aspek pengetahuan berada pada tahap tinggi dalam kajian ini. Sungguhpun begitu, tahap kesediaan yang tinggi dari aspek pengetahuan terhadap pembelajaran berasaskan bahan yang didapati dalam kajian ini adalah bertepatan dengan pendapat Cowgill II dan Waring (2017), Tally dan Goldenberg (2005), Cameron, Meter dan Long, (2016), Stoddard, 2012; Vansledright dan Kelly (2015), Pragnotti \& Russel III, 2001; Scheiner-Fisher, (2014) dan Reisman, (2012) yang mencadangkan agar pembelajaran berasaskan bahan-bahan sejarah perlu dilaksanakan secara meluas dalam proses pengajaran sejarah pada semua peringkat persekolahan disebabkan ianya dapat meningkatkan penguasaan pemahaman, pemikiran kritis dan minat belajar.

Jadual 3: Kesediaan Terhadap Pembelajaran Berasaskan Bahan Dari Aspek Pengetahuan

\begin{tabular}{lllcc}
\hline Konstruk & $\boldsymbol{N}$ & $\begin{array}{c}\text { Min } \\
(\boldsymbol{M})\end{array}$ & $\begin{array}{c}\text { Sisihan Piawai } \\
(\boldsymbol{S D})\end{array}$ & Tahap \\
\hline Pengetahuan & 60 & 4.10 & 0.66 & Tinggi \\
\hline
\end{tabular}

\section{Tahap Kesediaan Terhadap Pembelajaran Berasaskan Bahan dari Aspek Kemahiran}

Berdasarkan Jadual 4, tahap kesediaan terhadap pembelajaran berasaskan bahan dari aspek kemahiran $(M=4.10, S D=0.57)$ berada pada tahap tinggi. Justeru, dapat dirumuskan bahawa tahap kesediaan terhadap pembelajaran berasaskan bahan dari aspek kemahiran berada pada tahap tinggi dalam kajian ini. Tahap kesediaan dari aspek kemahiran yang tinggi yang dilaporkan dalam kajian ini disebabkan oleh murid-murid dapat meningkatkan kemahiran menggunakan bahan-bahan sejarah apabila mereka mempunyai sifat ingin tahu yang tinggi dan mampu untuk meneroka untuk menguasai pengetahuan sejarah yang diperlukan selaras dengan cadangan pengajaran dan pembelajaran dalam kurikulum sejarah yang mencadangkan pelaksanaan kajian kes dalam meningkatkan dan mengaplikasikan kemahiran pemikiran sejarah dalam ilmu sejarah (PPK, 2016). Saranan ini adalah bertepatan dengan pendapat Attalah, (2019), Johansson, (2017), Patterson, Lucas dan Kithinji, (2012), Shakila Yacob, Rosilawati Zainol, Ling dan Mona Massod, (2014), Ahmad Kamal Arifin Mohd Rus, (2014) dan Nokes (2007) yang menjelaskan bahawa pembelajaran berasaskan bahan dan media-media baharu yang 
telah membolehkan murid-murid tidak hanya bergantung kepada maklumat dalam buku teks sahaja, malah mereka dapat mengumpul dan mengkaji pelbagai bahan-bahan pembelajaran yang lain sama ada dalam bentuk asli mahupun dalam bentuk olahan dalam menjana proses pemahaman dan pemikiran aras tinggi dan kritikal mereka.

Jadual 4: Kesediaan Terhadap Pembelajaran Berasaskan Bahan Dari Aspek Kemahiran

\begin{tabular}{lllcc}
\hline Konstruk & $\boldsymbol{N}$ & $\begin{array}{c}\text { Min } \\
(\boldsymbol{M})\end{array}$ & $\begin{array}{c}\text { Sisihan Piawai } \\
(\boldsymbol{S D})\end{array}$ & Tahap \\
\hline Kemahiran & 60 & 4.10 & 0.57 & Tinggi \\
\hline
\end{tabular}

\section{Tahap Kesediaan Terhadap Pembelajaran Berasaskan Bahan dari Aspek Sikap}

Berdasarkan Jadual 5, tahap kesediaan terhadap pembelajaran berasaskan bahan dari aspek sikap $(M=4.06, S D=0.66)$ berada pada tahap tinggi. Justeru, dapat dirumuskan bahawa tahap kesediaan terhadap pembelajaran berasaskan bahan dari aspek sikap berada pada tahap tinggi dalam kajian ini. Tahap kesediaan dari aspek sikap yang tinggi yang dilaporkan dalam kajian ini adalah disebabkan minat, penyertaan aktif, sifat berdikari dan keyakinan murid-murid terhadap mata pelajaran sejarah yang baik yang membolehkan mereka berupaya untuk melibatkan diri dengan proses pembelajaran sejarah yang mendalam dengan menggunakan koleksi bahan-bahan sejarah yang dibekalkan di dalam kelas mahupun yang diterokai di luar kelas (Muraina, 2015; Huberman, 2009; Kasvikis, 2016; CetinDindar, 2016; Nersater, 2019; Hover et al. 2016; Ceceanu, 2014; Kipping, Wadhwani \& Bucheli, 2013). Oleh yang demikian, pembelajaran berasaskan bahan dapat membentuk proses pembelajaran yang menarik dan bermakna dalam membina minat terhadap mata pelajaran sejarah sebagai satu disiplin ilmu dinamik dan melahirkan murid-murid yang dapat bersaing pada peringkat global (PPK, 2018; KPM, 2013).

Jadual 5: Kesediaan Terhadap Pembelajaran Berasaskan Bahan Dari Aspek Sikap

\begin{tabular}{lllcc}
\hline Konstruk & $\boldsymbol{N}$ & $\begin{array}{c}\text { Min } \\
(\boldsymbol{M})\end{array}$ & $\begin{array}{c}\text { Sisihan Piawai } \\
(\boldsymbol{S D})\end{array}$ & Tahap \\
\hline Sikap & 60 & 4.06 & 0.66 & Tinggi \\
\hline
\end{tabular}

\section{Kesimpulan}

Kesimpulannya, tahap kesediaan murid terhadap pembelajaran berasaskan bahan dalam mata pelajaran sejarah berada pada tahap tinggi yang memberikan implikasi kepada para guru untuk menggunakan kepelbagaian bahan-bahan pembelajaran dalam proses pengajaran dan pembelajaran dengan lebih meluas lagi. Justeru, semua pihak perlu berganding bahu dalam pelaksanaan pengajaran dan pembelajaran berasaskan bahan secara bersepadu dan bersistematik dengan menekankan aplikasi pendekatan pembelajaran berpusatkan murid, strategi pembelajaran abad ke-21 dan menggalakkan penglibatan aktif murid bagi membentuk suasana persekitaran pembelajaran yang bermakna yang dapat menarik minat belajar sejarah yang berkesan.

\section{Rujukan}

Abdul Razaq Ahmad. (2014). Determination of teaching aids and methods to inculcate thinking skills in history subject. International Journal for Historical Studies, 6(1), 1-12.

Attalah, A. A. .H. (2019). The impact of the strategy of outstanding paintings on the development of the skills of historical thinking among the first grade intermediate. Journal of Tikrit University of Humanities, 26(2), 289-318.

Barton, K.C. (2005). Primary sources in history: Breaking through the myths.Phi Delta Kappan, $86(10), 745-753$. 
Bickford II, J.H., \& Bickford, M.S. (2015). Historical thinking, reading and writing about world's newest nation, South Sudan. Social Studies Research and Practice, 10(2), 111- 123.

Bickford III, J.H. (2010). Complicating students' historical thinking through primary sources reinvention. Social Studies Research \& Practices, 5(2), 47-60.

Brown, C.A., \& Dotson, K. (2007). A Case Study Using Digital Primary Source Documents. TechTrends, 51(3), 30-37.

Cameron, C., Meter, P.V., \& Long, V.A. (2016). The Effects of Instruction on students' Generation of Self-Questions When Reading Multiple Documents. The Journal of Experimental Education, 118.

Ceceanu, M. T. (2014). Learning by researching historical document and relics: Proceedia Social and Behavioral Science, 180, 286-292.

Cetin-Dindar, A. (2016). Student motivation in constructivist learning environment. Eurasia Journal of Mathematics, Science \& technology Education, 12(2), 233-247.

Cowgill II, D.A., \& Waring, S.M. (2017). Historical Thinking: An Evaluation of Student and Teacher Ability to Analyze Sources. Journal of Social Studies Education Research. 8(1), 115-145.

Cuenca, A \& Zaker, J. (2019). The use and ultility of video representatives in early social students field experiences. CITE Journal, 1-31.

Cummings, C. (2011). "Candyshack" teaching aids: using the films of Harold Ramss to teach social studies. Teacher preparations. The International Society for the Social Studies Annual Conference Proceedings, 1, 34-38.

Doiron, R., \& Davies, J. (1998). Partners in learning: Students, teachers, and the school library. Englewood: Libraries.

Dutt-Doner, K., Cook-Cottone, C., \& Allen, S. (2007). Improving classroom instruction: understanding the development nature of analyzing primary sources. Research in Middle Level education, 30(6), 1-20.

Gaffield, C. (2000). Primary sources, historical thinking, and the emerging redefinition of the B.A. as a research degree. Facsimile, 12-17.

Gaudelli, W. (2009). Secondary students reading of visual texts. Social Studies Teacher Education: Dare we teach for democracy? 36(1), 111-130.

Godsell, S. (2019). 'Poetry as method in the history classroom: Decolonising possibilities. Yesterday \& Today, 21, 1-28.

Greenhow, C., Dexter, S., \& Riedel, E. (2006). Methods for evaluating online resource based learning environments for teachers. Journal of Computing in Teacher Education, 23(1), 21 - 28.

Halida Yu, A. Abrizah \& Moh Khir Johari Abdullah Sani. (2016). Information literacy through recources-based learning: Malaysian teacher's conception and Instructional Practices. Malaysian Journal of Libraray \& Information Sciences, 21, 53-67.

Hannafin, M., \& Hill, J. (2007). Resource based learning. In J. Michael Spector, M. David Merrill, J. Van Merrienboer, \& P. Marcy Driscoll, (Eds.), Handbook of research on educational communications and technology, ( $3^{\text {rd }}$ ed.), (pp.525-536). New York: Lawrence Erlbaum Associates.

Haycock, C.A. (1991). Resource-based learning: A shift in the roles of teacher, learner. NASSP Bull, $75(535), 15-22$.

Hendrickson, L. (2016). Teaching with artifacts and special collections. Bulletin of the history of medicine, 90(1), 136-140.

Hill, J.R., \& Hannafin, M. J. (2001). Teaching and Learning in digital environments: The resurgence of resource-based learning. Education Technology Research Development, 45(4), 37-64.

Hover, S.V., Hicks, D., \& Dack, H. (2016). From Source to Evidence? Teachers' Use of Historical Sources in Their Classrooms. The Social studies, 107(6), 209-217.

Howard, T. (2019). How do students engage with visual sources in the teaching and learning history? British Educational Reasearch Journal, 1-15.

Huberman, A. (2009). The Use of authentic materials in the secondary Spanish Classroom. Studies in Teaching - 2009 Research Digest, 43-48.

Huot, B., Stroble, B., \& Bazerman, C. (2004). Multiple literacies for $21^{\text {st }}$ century. Cresskill: Hampton Press.

Johansson, P. (2017). Learning study as a clinical research practice to generate knowledge about the learning of historical primary source analysis. Educational Action Research, 25(1), 167-181. 
Kasvikis, K. (2016).Textbooks, teachers, historians and word of mouth, Greek students' ideas on how historical accounts are constructed. International Journal of Historical Learning, Teaching and Research, 13(2), 35-42.

Kementerian Pendidikan Malaysia. (2013). Pelan Pembangunan Pendidikan Malaysia 2013-2025. Putrajaya: Kementerian Pendidikan Malaysia.

Kementerian Pendidikan Malaysia. (2014). Elemen KBAT dalam sumber. Kementerian Pendidikan Malaysia: Bahagian Pembangunan Kurikulum.

Kipping, M., Wadhwani, D., \& Bucheli, M. (2014). Analyzing and Interpreting Historical Sources: A Basic Methodology. In M. Bucheli, \& D. Wadhwani (Eds.), Organizations in Time: History, Theory, Methods (pp. 305-330). Oxford: Oxford University Press.

Kong S. C., \& So, W. M. W (2008). A Study of building a resource- based learning environment with the inquiry learning approach: Knowledge of family trees. Computer \& Education, 50(1), 37-60.

Ling, W.A \& Mona Masood. (2014). The potential benefits of multimedia information represenatations in enhancing students critical thinking and history reasoning. International Journal of Social, Behaviour, Education, Bussiness and Industrial Engineering, 8(12), 38523855.

Mackey, M. (2002). Literacies across media: Playing the text. New York: Routledge.

Mardiani, N., Umasih \& Minarsih, M. (2019). Masteri sejarah masa hindu-buddha dan penggunaan sumber belajar sejarah dalam pembelajaarannya di SMK. Tamadun, 7(2), 328-347.

Melendres, G.O. (2015). Resource-based learning (RBL) Strategy to improve information literacy in general science of freshmen secondary students. Procceding of the 3th Global Summit on Education, 9-10 March 2015, Kuala Lumpur, 290-297.

Muraina, M.B. (2015). Oral tradition as a reliable source of historical writing arguments for and against and implications for historical writing in education. Historical Research Letter, 22, 17-21.

Nasyimah Ismail \& Zamri Mohamad. (2016). Sikap dan kesediaan pelajar sekolah menengah terhadap kemahiran berfikir aras tinggi dalam pembelajaran komsas bahasa melayu. Jurnal Pendidikan Bahasa Melayu, 6(2), 59-67.

Nersater, A. (2019). Students' understanding of historical sources - A composite ability. NORDIDACTICA - Journal of Humanities and Social Science Education, 1, 105-131.

Neumann, D. (2015). Secondary sources in history classrooms: Disciplinary framework and student learning. Social Education, 79(4), 204-210.

Nokes, J.D. (2014). Elementary students' Roles and Epsitemic Stances during Document Based History Lessons. Theory \& Research in Social Education, 42, 375-413.

Nokes, J.D. (2017). Historical Reading and writing in secondary school classrooms. In M.Carretero et al. (eds.), Palgrave Handbook of Research in Historical Culture and Education, 553- 571.

Nokes, J.D., Dole, J.A., \& Hacker, D.J. (2007). Teaching High School Students to Use Heuristics While Reading Historical Texts. Journal of Educational Psychology, 4(9), 1-13.

Noraini Bidin \& Zamri Mohamad (2016). Kesediaan murid sekolah menengah terhadap pelaksanaan pentaksiran berasaskan sekolah dalam mata pelajaran bahasa melayu. Juranl Pendidikan BahasaMelayu, 6(1), 64-76.

Nunnally, J.C. (1978). Psychometrie Theory $\left(2^{\text {nd }}\right.$ ed). New York: McGraw Hill.

Patterson, N.C., Lucas, A.G., \& Kithinji, M. (2012). Higher Order Thinking in Social Studies: An analysis of Primary Source Document Use. Social studies Research and Practice, 7(2), 68-85.

Pragnotti, J \& Russell III, W.B. (2011). Teaching history content with video game. The International Society for the Social Students Annual Conferences Proceedings, 1, 98-114.

Pusat Perkembangan Kurikulum. (2018). Dokumen Standard Kurikulum dan Pentaksiran Mata Pelajaran Sejarah Tingkatan Empat dan Lima. Putrajaya: Kementerian Pendidikan Malaysia.

Reisman, A. (2012). The "Document-Based Lesson": Bringing Disciplinary inquiry into high school history classrooms with adolescent struggling readers. Journal of Curriculum Studies, 44(2), 233264.

Reisman, A., \& Fogo, B. (2016). Contributions of educative document based curricular materials to quality of historical instruction. Teaching and Teacher Education, 59, 191-202.

Ryan, M., Wells, J., Freeman, A., \& Hallam, G. (1996). Resource based learning strategis: Implications for students and institutions. ALT-J: Journal of the Association for Learning Technology, 4(1), 93-98. 
Samuelsson, J., \& Wendell, J. (2016). Historical thinking about sources in the context of a standardsbased curriculum: A Swedish case. The Curriculum Journal, 27(4), 479-499.

Scheiner-Fisher, C. (2014). Using SOURCES to allow digital natives to explore the Lewis and Clark Expedition. Middle School Journal, 45(4), 3-12.

Shakila Yacob, Rosilawati Zainol, Ahmad Kamal Arifin Mohd Rus (2014). History and the new media: Teaching form five history in Malaysia: Prospects and challenge. EDULEARNING, Conference, July 2014, Barcelona Spain.

Sri Wahyuni Marimum \& Anuar Ahmad. (2019). Tahap kesediaan pelajar melayu mempelajari mata pelajaran sejarah di sekolah aliran cina (SRJKC) menggunakan bahasa mandarin dan hubungannya dengan pencapaian. International Journal of Humanities, Philosophy and Language, 2(7), 93-106.

Stoddard, J.D. (2012). Film as a 'thoughtful medium for teaching history. Learning, Media and Technology, 37(3), 271-288.

Swartz, E. E. (2012). Distinguishing themes of cultural responsiveness: A study of document-based learning. The Journal of Social Studies Research, 36(2), 135-167.

Tajularipin Sulaiman \& Mohd Majid Konting (2014). Kesediaan murid tahun 1 mengikuti pengajaran kemahiran proses sains dalam bahasa Inggeris. Jurnal Kepimpinan Pendidikan, 1(1), 1-6.

Tally, B., \& Goldenberg, L.B. (2005). Fostering Historical Thinking with Digitized Primary Resources. Journal of Research on Technology in Education, 38(1), 1-21

Tuan Rahayu Tuan Lasan, Mohd Adari Che Noh \& Mohd Isa Hamzah. (2017). Pengetahuan, sikap dan kesediaan murid terhadap kemahiran berfikir aras tinggi (KBAT) dalam mata pelajaran Tasawwur Islam. Tinta Artikulasi Membina Ummah, 3(1), 15-28.

VanSledright, B.A., \& Kelly, C. (1998). Reading American History: The Influence of Multiple Sources on Six Fifth Graders. The Elementary School Journal, 98(3), 239-265.

Wiley, J., \& Voss, J.F. (1999). Constructing arguments from multiple sources: Tasks that promote understanding and not just memory for text. Journal of Educational Psychology, 91(2), 301-311. 